\title{
Creating Positive Learning Environments: Antecedent Strategies for Managing the Classroom Environment \& Student Behavior
}

\author{
Tachelle Banks \\ Cleveland State University, Department of Teacher Education, Cleveland, USA \\ Email: t.i.banks@csuohio.edu
}

Received 25 December 2013; revised 25 January 2014; accepted 2 February 2014

Copyright (C) 2014 by author and Scientific Research Publishing Inc.

This work is licensed under the Creative Commons Attribution International License (CC BY). http://creativecommons.org/licenses/by/4.0/

(c) (i) Open Access

\begin{abstract}
Teacher conceptualization of behavior problems is important in determining what strategies are used to prevent problematic classroom behavior. If teachers view a student's behavior as symptomatic of a poorly organized classroom, they may seek ways of reorganizing the environment to maximize occasions for occurrence of appropriate behavior and the prevention of behavior problems. That is, teachers consider antecedent approaches and attempt to set the occasion for appropriate behavior to occur. This article will describe approaches for setting up antecedent classroom strategies designed to prevent problematic behavior and subsequently enhance classroom management plans.
\end{abstract}

Keywords

Antecedent Strategies, Classroom Management, Behavior Management

\section{Introduction}

Students with behavioral and emotional disorders characteristically demonstrate inconsistent responses to teacher requests and display behaviors that are disruptive to the classroom environment. Although teachers prefer positive interventions over punishment to manage classroom behavior, many classrooms are not actually positive learning environments. Westling (2010) found that most teachers did not use effective classroom management strategies and scrutinized challenging student behavior as having a negative impact on the overall classroom environment and subsequent interactions between students and teachers.

Strong classroom organization and behavior management skills are critical for both general education and special education teachers (Oliver \& Reschly, 2010). Using methods that produce and increase constructive in- 
teractions will result in more successful and classroom environments for both teachers and students. This article provides a review of effective classroom management strategies that are designed to create positive learning environments by building in positive supports that will prevent challenging classroom behavior prior to the implementation of more reactive behavioral approaches.

Teachers should work toward creating positive learning environments and therefore be able to identify and remediate classroom conditions that may make it more likely that desirable behaviors occur in the classroom (Hardman \& Smith, 1999). When teachers create environments of care, they create settings where potential challenges are planned for, rules and consequences are established, positive behavior is the focus for classroom supports, redirection rather than reprimand is the vehicle behavior change, and students are offered a variety of choices to reach an agreed-upon instructional goal. Teachers that create positive classrooms pay close attention to all of the environmental stimuli that are present in their educational setting.

Classroom management is a multifaceted and scientific process. It is important that teachers learn how to discriminate between problematic behaviors that are best addressed by contingency management and problems that are better addressed by other approaches designed to modify behavior. Mild but potentially disruptive behavior problems may often be due to poor classroom structure. The structure of the classroom environment may influence student's behavior in ways that does not always require teacher intervention but consideration of how the environment is organized (Smith \& Misra, 1992). For example, teachers can control mild problematic behaviors during some group activities just by making sure that seating conditions are not crowded. Prevention of problematic behaviors is an essential part of classroom behavior management. Therefore, antecedent stimulus and strategies that promote prevention are integral components of a comprehensive classroom management program.

The first component of an effective classroom management program is the application of antecedent techniques. Teachers can identify and implement preventative techniques to prompt appropriate behavior and minimize disruptive behaviors in the classroom (Conroy, Sutherland, Snyder, \& Marsh, 2008). Empirical studies support the notion of a specific level of management strategies. Active supervision, creating a list of rules, lessons that teach behavioral expectations, and monitoring student progress were themes derived from the literature. Techniques discussed in the following sections are appropriate for all students, regardless of the presence of a disability including arrangement of the classroom, classroom schedule, classroom rules, and teacher-student interactions.

\section{Physical Arrangement of the Classroom Environment}

Accessibility and organization are key aspects when designing the physical arrangement of the classroom. The physical arrangement of the classroom assists with the prevention of problematic classroom behavior by making sure that materials and resources for students are readily available. Teachers can establish routines for distributing, using, returning, and storing materials in an effort to prevent confusion. Some suggestions for setting up routines include designating shelf space for supplies, basal readers, dictionaries, and class and homework assignments; developing and teaching procedures for borrowing materials; and routinely assigning the distribution of materials on a rotating basis so that all students get an opportunity to distribute supplies (Smith \& Misra, 1992). Advanced planning with regard to the selection and distribution of materials maximizes instructional time and makes the environment more predictable.

Seating arrangements have implications for teacher-directed instruction (Nordquist \& Twardosz, 1990). If given the option, students will often sit next to their friends, most who are similar to themselves and have the same interests and ability. In typical situations, students who sit in the front of the classroom, in most cases, are more likely to receive reinforcement from the teacher. Teachers tend to direct most of their attention toward students in the front of the group because they are prone to actively participate in the lesson, answer questions, or make relevant comments. Students sitting in the back of the group often receive less attention and do not benefit equally from instruction. Therefore, the actual arrangement of the classroom directly impacts classroom instruction and interactions. Consequently, teachers should strategically plan seating arrangements. For example, students can be arranged in a strewn pattern deviating from the typical classroom setup. Students who typically sit in front of the group can be arranged so that they are scattered throughout the room and sit in closer proximity to students who would typically sit on the sides or in back of the group to potentially serve models or provide assistance to their peers, when needed. Table 1 includes questions that may assist teachers in developing management systems prior to the onset of problematic behaviors, with regard to physical environment. 
Table 1. Guiding questions regarding the physical arrangement of classrooms.

\begin{tabular}{cl}
\hline Classroom environment & \multicolumn{1}{c}{ Questions to ask yourself... } \\
\hline Classroom structure & How easy is it for students to move around the classroom? \\
Is it easy or difficult to maneuver around the classroom? & Will they bump into any furniture? \\
Student areas & Are the students' desks positioned too far or too close together? \\
& Are there any stimuli in the environment that serves as a distraction to students? \\
\hline
\end{tabular}

\section{Classroom Schedule}

Clear classroom expectations increase the likelihood that students will be successful in understanding what is expected of them. The classroom schedule allows the class members and teacher to anticipate what will happen during a school day. Guidelines for schedule development are as follows.

1) Teachers should seek student suggestions after ruling out nonnegotiable events and time slots.

For example, time scheduled for art or music is $1 \mathrm{pm}$ on Tuesday and Thursday; the scheduling of this event is nonnegotiable. Negotiable events can be presented to students and discussed.

2) The schedule should be on permanent display in a format that reflects the age and abilities of the students.

3) Use the Premack Principle.

The Premack Principle states that students are more likely to engage in a low probability activity if they know it will be followed by a high probability activity that they enjoy (Premack, 1959). For example, if students generally dislike math, a low probability activity, the teacher may try to schedule a high probability activity, gym, after math.

4) The length of the activity should reflect the student's abilities.

Consider the attention span of your group. Elementary students can be expected to attend to an activity for 20

- 30 minutes. Secondary students can be expected to attend to an activity for 30 - 40 minutes.

5) Avoid revising the schedule.

It is important that the schedule becomes predictable for students. Changing the schedule will decrease the likelihood of predictability and limit the students' ability to anticipate events during the day. If revisions are necessary, they should be announced and posted as soon as possible.

6) The schedule should motivate students.

Interesting activities should be prepared in case the planned activity is completed sooner than anticipated.

7) Students' efforts should be reinforced.

8) Send a copy of the class schedule to families (Smith \& Misra, 1992).

Table 2 includes questions that teachers can ask themselves regarding class routines and scheduling.

\section{Classroom Rules}

Developing classroom rules is a critical step toward increasing positive interactions and communicating in advance the expectations for classroom behavior and the consequences. Rules help teachers identify which behaviors to positively reinforce and define which behaviors will elicit approval from the teacher. Therefore, rules serve as an effective antecedent control technique when developed and implemented properly (Hardman \& Smith, 1999). Classroom rules should also be linked to positive consequences and not exclusively to punishment and should be established at the beginning of the school year. Examples of effective classroom rule development includes the following:

1) State the rules positively and allow students to participate in development.

a) Rules should result from a discussion involving the teacher and the class members.

b) Discussions can begin by identifying safety rules for the community and the rationale for having them and should also include potential consequences for violation of classroom rules.

2) The number of rules should be relatively small and should be stated positively, clearly, and succinctly.

a) Limit the rules to no more than seven.

b) Clearly post four or five positively stated, behaviorally based rules (Musser, Bray, Kehle, \& Jenson, 2001).

3) Display rules in a prominent place and teach in a manner that is consistent with the way in which traditional academics are taught. 
Table 2. Guiding questions regarding classroom routines and schedules.

\begin{tabular}{cl}
\hline Clarify classroom behavior expectations & \multicolumn{1}{c}{ Questions to ask yourself $\ldots$} \\
\hline \multirow{3}{*}{ Teacher considerations } & How well are classroom procedures defined? \\
& Is the daily routine predictable? \\
& Is the classroom schedule visible to students? \\
& Are transition periods considered as a part of the daily schedule? \\
Student outcomes & Do students know what to do throughout the day? \\
& What are possible elements that may cause distractions for students in \\
& the learning environment?
\end{tabular}

4) Present and model each rule.

Considerable time should be spent during the beginning weeks of school introducing rules and procedures.

5) Consistently monitor the adherence to classroom rules.

Precision thwarts misinterpretations and misuse of rules by students and makes it possible to consistently apply consequences for violations. Not only do students need to help with defining rules; they need to understand them. One way to ensure student ownership of classroom rules is to include them in the process (Smith \& Misra, 1992). Rule-making needs to be a collaborative exercise where teachers and students discuss the importance of establishing a safe classroom environment and participate in the collective development of rules. In addition, teachers should develop a system where the rules are taught, modeled, and reinforced consistently and positively (Hardman \& Smith, 1999).

It can be difficult for teachers to monitor and enforce more than seven rules and therefore may be unreasonable to expect students to remember and comply with several rules at one time. Classroom rules should be readily available for easy reference and serve as a reminder to adhere to classroom expectations. Rules may be reviewed and revised as often as necessary to reinforce automaticity and student ownership. Consistency is a vital component of a comprehensive classroom management plan. When issuing rewards and consequences based on student behavioral responses, teachers should be sure to apply and reinforce the classroom rules by praising students who are following the rules and implementing consequences for those who do not. Table 3 offers some questions that teachers may ask themselves with regard to rule development and student involvement.

When both teachers and students develop the rules, both are responsible for a creating a positive learning environment. Reinforcing classroom rules consistently is the most important skill a teacher can implement to produce positive interactions (Hardman \& Smith, 1999). One strong method for consistent rule reinforcement is the use of a token economy. This is a formalized and systematic attempt to deliver positive reinforcement in which teachers give token reinforcers to students for following the rules. Tokens can then be traded for a variety of events or items. Teachers and students can work together to determine a value for following the rules and a schedule of when the students will be reinforced for following the rules. Most problems can be identified using two questions to analyze the students' actions. If problems develop, the teacher should review the plan by asking:

1) Does the student believe that they can achieve the level of behavior acquired?

2) Is the reinforcement being given often enough and is it something the student wants?

\section{Teacher Student Interactions \& Peer Modeling}

In an effort to create a positive learning environment, teachers can address problematic classroom behaviors by developing appropriate relationships with students that help them feel more comfortable in academic settings. Lane, Pierson, Stang, \& Carter (2010) examined teachers' expectations of student behavior. The results reiterated the importance of teacher student interactions. The researchers noted the importance of purposeful planning, and building effective communication and suitable relationships in an effort to promote positive behavior change at all grade levels. Suggestions for building appropriate teacher student relationships include talking to student in concrete terms, balancing praise and corrective feedback, identifying alternatives to appropriate behaviors, and understanding how cultural and linguistic differences impact peer and adult interactions in classroom settings (Ford \& Kea, 2009; Smith \& Misra, 1992).

At times, teachers may find themselves directing critical remarks toward a particular student. Teachers should 
Table 3. Guiding questions regarding rule development and student involvement.

\begin{tabular}{cl}
\hline Clear expectations and rules & Questions to ask yourself... \\
\hline Teacher considerations & Is the setting designed to encourage appropriate behavior in the classroom? \\
& Are the rules developed in such a manner to prevent less than desirable behavior? \\
& Are the rules stated in simple and observable terms? \\
What are the positive consequences for students engaging in desirable behaviors? & Are students involved in the rule making process for the learning environment? \\
& Do students know exactly what the classroom rules are and consequences? \\
\hline
\end{tabular}

speak to students in concrete terms, using vocabulary and syntax that is appropriate for the students' comprehension levels. It is important that teachers not only set up opportunities for students to be successful and praise their efforts but also take advantage of teachable moments to provide feedback and assist students with modifying classroom behavior that disrupts the learning environment. As a result, praise and criticism should be specific so that students can identify which aspects of their behavior are being addressed.

Helping students identify alternatives to inappropriate behaviors results in the promotion of positive behavior change. Teachers should keep in mind that the alternative behavior should be an incompatible behavior that serves the same function as the problematic classroom behavior. This decreases the likelihood that the student will be able to engage in the desired behavior and the problematic behavior at the same time. For example, a student cannot impulsively walk around that classroom and remain in an assigned area at the same time. To encourage more appropriate behavior that may serve the same function, the student can obtain permission to walk around in a designated area. By providing increased opportunities for engaging in the suitable alternative behavior that serves the same function, teachers will create learning environments that prompt positive behavior change. Creating opportunities for students to be successful will increase the likelihood that students will choose to engage in desirable behaviors and student efforts should be positively reinforced. Therefore, the alternative behavior should be just as rewarding as engaging in less than desirable behaviors.

Poor classroom management interferes with teaching and learning (Conroy et al., 2008). Meeting the diverse learning needs of all students is a reality that teachers have to face. Rosas and West (2009) investigated teachers' beliefs on classroom management. The results supported what is commonly known, that teachers consistently identify classroom management as a major concern. Creating effective and positive learning environments entails understanding non-cognitive differences and getting to know students.

Ford and Kea (2009) suggested that teachers use culturally responsive instruction defined as responding proactively and empathetically to student differences to meet the diverse educational and socio-emotional needs of students. Cultural and linguistic differences add complexity to what can be a very daunting task for some teachers. Environments that support diversity and difference are necessary entities for facilitating positive behavior change and cultivating inviting classrooms. To be culturally responsive, teachers should strive toward understanding cultural and linguistic differences and the associated needs of students from various cultural backgrounds (Ford \& Kea, 2009).

\section{Conclusion}

This article discussed antecedent strategies designed to prevent challenging classroom behavior. Teachers can identify, plan for, and implement preventative techniques to encourage positive student behavior and minimize disruptive behaviors in the classroom. We described simple and effective techniques that teachers should implement in an effort to create positive learning environments. Teachers should take an active role in seating arrangements and make sure that students experience an appropriate rate of success. Classroom rules communicate in advance the expectations for classroom behavior and increase the likelihood for students to be successful. Balancing praise with corrective feedback and understanding the impact of cultural and linguistic differences to establish and maintain appropriate teacher-student interactions are essential skill sets for all teachers. Utilizing effective antecedent strategies to create positive learning environments are key aspects of a comprehensive classroom management program. 


\section{References}

Conroy, M., Sutherland, K., Snyder, A., \& Marsh, S. (2008). Classwide Interventions. Teaching Exceptional Children, 40, 24-30.

Ford, D. Y., \& Kea, C. T. (2009). Creating Culturally Responsive Instruction: For Students' and Teachers' Sakes. Focus on Exceptional Children, 41, 1-16.

Hardman, E., \& Smith, S. W. (1999). Promoting Positive Interactions in the Classroom. Intervention in School \& Clinic, 34, 178-201. http://dx.doi.org/10.1177/105345129903400311

Lane, K. L., Pierson, M. R., Stang, K. K., \& Carter, E. W. (2010). Teacher Expectations of Students’ Classroom Behavior. Remedial \& Special Education, 31, 163-174. http://dx.doi.org/10.1177/0741932508327464

Musser, E. H., Bray, M. A., Kehle, T. J., \& Jenson, W. R. (2001). Reducing Disruptive Behaviors in Students with Serious Emotional Disturbance. School Psychology Review, 30, 294-305.

Nordquist, V. M., \& Twardosz, S. (1990). Preventing Behavior Problems in Early Childhood Special Education Classrooms through Environmental Organization. Education \& Treatment of Children, 13, 274-282.

Oliver, R. M., \& Reschly, D. J. (2010). Special Education Teacher Preparation in Classroom Management: Implications for Students with Emotional and Behavioral Disorders. Behavioral Disorders, 35, 188-199.

Premack, D. (1959). Toward Empirical Laws: I. Positive Reinforcement. Psychological Review, 66, 219-233. http://dx.doi.org/10.1037/h0040891

Rosas, C., \& West, M. (2009). Teachers Beliefs about Classroom Management: Pre-Service and Inservice Teachers’ Beliefs about Classroom Management. International Journal of Applied Educational Studies, 5, 54-61.

Smith, M. A., \& Misra, A. (1992). A Comprehensive Management System for Students in Regular Classrooms. The Elementary School Journal, 92, 353-371. http://dx.doi.org/10.1086/461697

Westling, D. (2010). Teachers and Challenging Behavior: Knowledge, Views, and Practices. Remedial \& Special Education, 31, 48-63. http://dx.doi.org/10.1177/0741932508327466 